\title{
ANALISA PERAWATAN MESIN PULPER MENGGUNAKAN METODE OVERALL EQUIPMENT EFFECTIVENESS (OEE)
}

\author{
Ade Mukhlis Shoutul Ahlaq, Dadi Cahyadi, Firdanis Setyaning Handika \\ Program Studi Teknik Industri, Fakultas Teknik, Universitas Serang Raya \\ Email: ademukhlisshoutulahlaq@gmail.com; dadicahyadi2012@gmail.com; \\ firdanishandika@gmail.com
}

\begin{abstract}
Abstrak - Penelitian ini bertujuan untuk mengetahui efektivitas mesin Pulper. Penelitian dilakukan dengan menggunakan metode Overall Equipment Effectiveness. Penelitian dilakukan di perusahaan yang bergerak di bidang Pulp \& Paper. Data dikumpulkan dengan wawancara dan melakukan observasi langsung di lapangan selama bulan februari 2017. Berdasarkan penelitian dapat disimpulkan bahwa Nilai OEE mesin Pulper diperoleh $77.31 \%$ dengan faktor utama penyebab kerusakan yaitu ragger putus sebesar $46 \%$. Usulan perbaikan yang dapat diberikan untuk meminimalkan kejadian ragger putus adalah pelatihan operator mesin ragger secara berkala, perencanaan perawatan mesin ragger yang terschedule serta penyediaan alat bantu untuk mempermudah operator memperbaiki mesin yang rusak
\end{abstract}

Kata kunci: Mesin Pulper; Overall Equipment Effectiveness; Perawatan Mesin

\begin{abstract}
This study aims to determine the effectiveness of Pulper machines. The research was conducted using the Overall Equipment Effectiveness method. The research conducted at a company engaged in the Pulp \& Paper field. Data collected by interviews and conducting direct observations in the area during February 2017. Based on the research, it can conclude that the Pulley OEE value was obtained by $77.31 \%$ with the main factor causing damage was Broken Ragger by $46 \%$. The proposed improvements that can be given to minimize the incidence of broken ragger are training of ragger machine operators regularly, planning maintenance of scheduled ragger machines as well as providing tools to make it easier for operators to repair damaged machines.
\end{abstract}

Keywords: Machine Maintenance; Overall Equipment Effectiveness; Pulper Machine

\section{PENDAHULUAN}

Perkembangan sektor industri pulp dan paper yang semakin pesat di Indonesia, tidak terlepas dari mesin Pulper. Mesin pulper adalah mesin yang digunakan untuk menghancurkan dan meleburkan kertas atau kardus untuk daur ulang. Selain itu proses terpenting yang berlangsung dalam sebuah perusahaan pulp dan paper adalah proses produksi dan perawatan fasilitas mesinnya.

Proses produksi merupakan faktor utama yang dapat meningkatkan perkembangan sebuah perusahaan. Apabila kapasitas produksi perusahaan meningkat, maka perusahaan akan semakin besar dan berkembang. Lancarnya suatu produksi harus diimbangi dengan perawatan terhadap mesin - mesin yang bekerja didalamnya rusaknya suatu mesin akan berpengaruh pada kapasitas produksi yang dihasilkan dan dapat merugikan perusahaan. Perawatan terhadap mesin - mesin produksi ini meliputi pengecekan dan pelumasan secara berkala dan melakukan penggantian suku cadang pada fasilitas mesin yang digunakan.

Perawatan yang dilakukan pada suatu mesin dalam sebuah perusahaan harus dilakukan dalam sebuah manajemen yang baik dan terkontrol. Hal ini dilakukan agar perusahaan dapat bekerja secara efisien dan dapat menekan atau mengurangi kerusakan yang mungkin terjadi.

Salah satu metode yang digunakan dalam perencanaan peralatan adalah Total Productive Maintenance (TPM). TPM merupakan metode yang berfokus pada peningkatan fungsi dan peralatan proses produksi (Chan, Lau, Ip, Chan, \& Kong, 2005; Swanson, 2001) dengan parameter Overall Equipment Effectiveness (Nakajima, 1988). TPM melibatkan peran serta aktif operator dalam mengidentifikasi kerusakan, melakukan perbaikan mandiri dalam skala kecil tanpa harus menunggu kerusakan peralatan yang lebih besar (Supriyadi, Ramayanti, \& Afriansyah, 2017). 
Sebuah perusahaan Pulp \& Paper yang berada di daerah memiliki beberapa departemen, salah satunya yaitu Departemen Paper Mesin A (PMA). PMA memproduksi kertas coklat yang berupa jumbo roll. Dalam pelaksanaan proses produksi, PMA tidak lepas dari permasalahan yang mengganggu proses produksi yang menyebabkan terganggunya proses produksi. Untuk itu perlu suatu penanganan untuk mengatasi masalah kerusakan tersebut.

Penelitian ini bertujuan mengetahui nilai Overall Equipment Effectiveness (OEE) mesin paper mesin A. Nilai ini diharapkan menjadi dasar perbaikan manajemen dalam meningkatkan nilai OEE sehingga lebih produktif dalam menunjang proses produksi.

\section{METODE PENELITIAN}

Penelitian ini dilakukan pada mesin pulper pada perusahaan Pulp \& Paper berdasarkan data historis perusahaan selama bulan maret 2016 sampai Februari 2017. Analisis data dilakukan dengan menghitung nilai Overall Equipment Effectiveness (OEE) sebagai dasar penentuan langkah perbaikan.

OEE didefinisikan sebagai ukuran kinerja suatu peralatan dalam menunjang proses produksi sesuai dengan yang telah ditetapkan (Bamber, Castka, Sharp, \& Motara, 2003; Muchiri
\& Pintelon, 2008; Williamson, 2006). Parameter OEE terdiri availability, performance dan quality. Nilai ketiga parameter tersebut dapat digunakan untuk mengidentifikasi efektivitas peralatan dalam periode tertentu (Dal, Tugwell, \& Greatbanks, 2000; Suhendra \& Betrianis, 2005).

Availability $=\frac{\text { Loading Time }- \text { Downtime }}{\text { Loading Time }} \times 100 \%$

Performance Efficiency =

$\frac{\text { Processed Amount } \times \text { Ideal Cycle Time }}{\text { Operation Time }} \times 100 \%$

Quality $=\frac{\text { Processed Amount }- \text { Defect Amount }}{\text { Processed Amount }} \times 100 \%$

$O E E=$ Availability $\times$ performance $\times$ Quality

\section{HASIL DAN PEMBAHASAN}

Data yang digunakan dalam penelitian ini adalah data laporan produksi dari bulan maret 2016 sampai februari 2017 (Tabel 1). Data ini digunakan sebagai dasar penentuan nilai OEE yang diperoleh. Data yang diperoleh diolah dengan terlebih dahulu menghitung Total Downtime, Ideal Cycle Time, Persentase Jam Kerja Mesin, dan Operation Time (Tabel 2).

Tabel 1. Data Produksi, Jam Kerja Mesin,Waktu Henti Mesin

\begin{tabular}{|r|r|r|r|r|r|r|}
\hline \multirow{2}{*}{ Bulan } & $\begin{array}{c}\text { Processed } \\
\text { Amount } \\
\text { (ton) }\end{array}$ & $\begin{array}{c}\text { Jam Kerja } \\
\text { Mesin } \\
\text { (menit) }\end{array}$ & $\begin{array}{c}\text { Planed } \\
\text { Downtime } \\
\text { (menit) }\end{array}$ & $\begin{array}{c}\text { Loading } \\
\text { Time } \\
\text { (menit) }\end{array}$ & $\begin{array}{c}\text { Breakdown } \\
\text { Time } \\
\text { (menit) }\end{array}$ & $\begin{array}{c}\text { Reject } \\
\text { Produk } \\
\text { (ton) }\end{array}$ \\
\hline Mar-16 & 11450 & 44640 & 3160 & 41480 & 975 & 275 \\
\hline Apr-16 & 7480 & 43200 & 4350 & 38850 & 2535 & 155 \\
\hline May-16 & 7745 & 44640 & 6560 & 38080 & 1550 & 225 \\
\hline Jun-16 & 7120 & 43200 & 4760 & 38440 & 1630 & 430 \\
\hline Jul-16 & 6530 & 44640 & 6240 & 38400 & 2430 & 230 \\
\hline Aug-16 & 7155 & 44640 & 5405 & 39235 & 2750 & 215 \\
\hline Sep-16 & 7860 & 43200 & 7255 & 35945 & 2305 & 170 \\
\hline Oct-16 & 9670 & 44640 & 4865 & 39775 & 1240 & 320 \\
\hline Nov-16 & 10260 & 43200 & 3565 & 39635 & 1220 & 335 \\
\hline Dec-16 & 7765 & 44640 & 5655 & 38985 & 1370 & 140 \\
\hline Jan-17 & 11460 & 44640 & 2250 & 42390 & 1140 & 200 \\
\hline Feb-17 & 9785 & 40320 & 2765 & 37555 & 970 & 235 \\
\hline
\end{tabular}


Tabel 2. Nilai Hasil Perhitungan Waktu Operasi dan Persentase Jam Kerja Mesin

\begin{tabular}{|r|r|r|r|r|}
\hline \multicolumn{1}{|c|}{ Bulan } & $\begin{array}{c}\text { Total } \\
\text { Downtime } \\
\text { (menit) }\end{array}$ & $\begin{array}{c}\text { Ideal Cycle } \\
\text { Time } \\
\text { (menit) }\end{array}$ & $\begin{array}{c}\text { Persentase } \\
\text { Jam Kerja } \\
\text { Mesin }\end{array}$ & $\begin{array}{c}\text { Operation } \\
\text { Time } \\
\text { (menit) }\end{array}$ \\
\hline Mar-16 & 4135 & 3.22 & $88.93 \%$ & 37345 \\
\hline Apr-16 & 6885 & 4.08 & $78.46 \%$ & 31965 \\
\hline May-16 & 8110 & 3.59 & $72.94 \%$ & 29970 \\
\hline Jun-16 & 6390 & 4.32 & $80.06 \%$ & 32050 \\
\hline Jul-16 & 8670 & 4.17 & $70.84 \%$ & 29730 \\
\hline Aug-16 & 8155 & 4.04 & $73.76 \%$ & 31080 \\
\hline Sep-16 & 9560 & 2.92 & $63.77 \%$ & 26385 \\
\hline Oct-16 & 6105 & 3.37 & $81.87 \%$ & 33670 \\
\hline Nov-16 & 4785 & 3.33 & $86.27 \%$ & 34850 \\
\hline Dec-16 & 7025 & 3.92 & $78.02 \%$ & 31960 \\
\hline Jan-17 & 3390 & 3.38 & $91.31 \%$ & 39000 \\
\hline Feb-17 & 3735 & 3.41 & $88.96 \%$ & 33820 \\
\hline
\end{tabular}

Downtime mesin merupakan waktu dimana mesin tidak dapat melakukan operasi sebagaimana mestinya karena adanya gangguan terhadap mesin Pulper. Rumus yang digunakan untuk menghitung Downtime adalah:

Downtime = Planned Downtime + Breakdown Time

$$
=3160+973=4135 \text { menit }
$$

Pada bulan maret 2016 diperoleh Total Downtime 4135 menit

Ideal Cycle Time merupakan waktu siklus ideal mesin dalam melakukan proses produksi terhadap produk kertas pada mesin Pulper. Untuk menghitung ideal cycle time maka perlu diperhatikan persentase jam kerja terhadap delay, dimana delay sama dengan total downtime. Rumus jam kerja yaitu:

$$
\begin{aligned}
\% \text { Jam Kerja }= & 1-\frac{\text { Loadingtime }- \text { Downtime }}{\text { Loading Time }} \\
& \times 100 \% \\
= & 1-\frac{41480-4135}{41480} \times 100 \% \\
= & 88.93 \% \\
\text { Waktu Siklus }= & \frac{\text { Loadingtime }}{\text { Total Produksi }} \\
= & \frac{41480}{11450} \\
= & 3.6 \text { menit }
\end{aligned}
$$

Waktu Siklus Ideal $=$ Waktu Siklus $\times$ Persentase Jam Kerja

$=3.6 \times 88.93 \%$

$=3.22$ menit
Operation time dapat dihitung dihitung dengan rumus:

Operation time $=$ Loading time - Total Downtime $=41480-4135=37345$ menit

Availability merupakan rasio dari tingkat ketersediaan operation time mesin Pulper terhadap loading time. Contoh perhitungan ketersediaan mesin Pulper pada bulan Maret 2016:

$$
\begin{aligned}
\text { Availability } & =\frac{41480-4135}{41480} \times 100 \% \\
& =90.03 \%
\end{aligned}
$$

Pada bulan maret 2016 nilai availability sudah memenuhi standar yaitu $90.03 \%$

Contoh perhitungan

Performance Efficiency bulan Maret 2016:

Performance Efficiency

$$
\begin{aligned}
& =\frac{11450 \times 3.22}{37345} \times 100 \% \\
& =98.77 \%
\end{aligned}
$$

Pada bulan maret 2016 nilai Performance Efficiency lebih besar $3.77 \%$ dari standar yaitu $98.77 \%$.

Rate of Quality Product merupakan suatu rasio yang menggambarkan kemampuan peralatan/mesin dalam menghasilkan produk yang sesuai dengan standar. Contoh perhitungan Rate of Quality Product bulan Maret 2016: 
Rate of Quality Product

$$
\begin{aligned}
& =\frac{11450-275}{11450} \times 100 \% \\
& =97.60 \%
\end{aligned}
$$

Pada bulan maret 2016 nilai Rate of Quality Product diperoleh $97.60 \%$ kurang dari standar yaitu $99.9 \%$.

Untuk mengetahui besarnya efektivitas mesin Pulper, maka terlebih dahulu harus diperoleh nilai-nilai Availability Ratio,
Performance Efficiency dan Rate Quality Product. Contoh perhitungan Nilai OEE pada bulan maret 2016 adalah

$\mathrm{OEE}=90,03 \% \times 98,77 \% \times 97,60 \%$

$$
=86,79 \% \text {. }
$$

Pada bulan maret 2016 nilai OEE sebesar $87,79 \%$ yang secara rata-rata sudah melebihi standar OEE sebesar 85\%. Secara rinci perhitungan OEE dapat dilihat pada tabel 3.

Tabel 3. Nilai OEE

\begin{tabular}{|r|r|r|r|c|}
\hline \multicolumn{1}{|c|}{ Bulan } & $\begin{array}{c}\text { Availability } \\
\text { Ratio }\end{array}$ & $\begin{array}{c}\text { Performace } \\
\text { Efficiency }\end{array}$ & $\begin{array}{c}\text { Rate Of Quality } \\
\text { Product }\end{array}$ & OEE \\
\hline Mar-16 & $90.03 \%$ & $98.77 \%$ & $97.60 \%$ & $86.79 \%$ \\
\hline Apr-16 & $82.28 \%$ & $95.36 \%$ & $97.93 \%$ & $76.83 \%$ \\
\hline May-16 & $78.70 \%$ & $92.68 \%$ & $97.09 \%$ & $70.82 \%$ \\
\hline Jun-16 & $83.38 \%$ & $96.02 \%$ & $93.96 \%$ & $75.23 \%$ \\
\hline Jul-16 & $77.42 \%$ & $91.50 \%$ & $96.48 \%$ & $68.34 \%$ \\
\hline Aug-16 & $79.21 \%$ & $93.12 \%$ & $97.00 \%$ & $71.54 \%$ \\
\hline Sep-16 & $73.40 \%$ & $86.87 \%$ & $97.84 \%$ & $62.39 \%$ \\
\hline Oct-16 & $84.65 \%$ & $96.71 \%$ & $96.69 \%$ & $79.16 \%$ \\
\hline Nov-16 & $87.93 \%$ & $98.11 \%$ & $96.73 \%$ & $83.45 \%$ \\
\hline Dec-16 & $81.98 \%$ & $95.17 \%$ & $98.20 \%$ & $76.61 \%$ \\
\hline Jan-17 & $92.00 \%$ & $99.24 \%$ & $98.25 \%$ & $89.71 \%$ \\
\hline Feb-17 & $90.05 \%$ & $98.78 \%$ & $97.60 \%$ & $86.82 \%$ \\
\hline Rata-rata & $83.42 \%$ & $95.20 \%$ & $97.11 \%$ & $77.31 \%$ \\
\hline
\end{tabular}

Hasil perhitungan Overall Equipment Effectiveness pada mesin Pulper pada bulan Maret 2016 - bulan Februari 2017 diperoleh rata - rata nilai Overall Equipment Effectiveness $77.31 \%$. Hasil ini menunjukan nilai Overall Equipment Effectiveness mesin Pulper rendah dibawah standar yang ada yaitu $85 \%$.

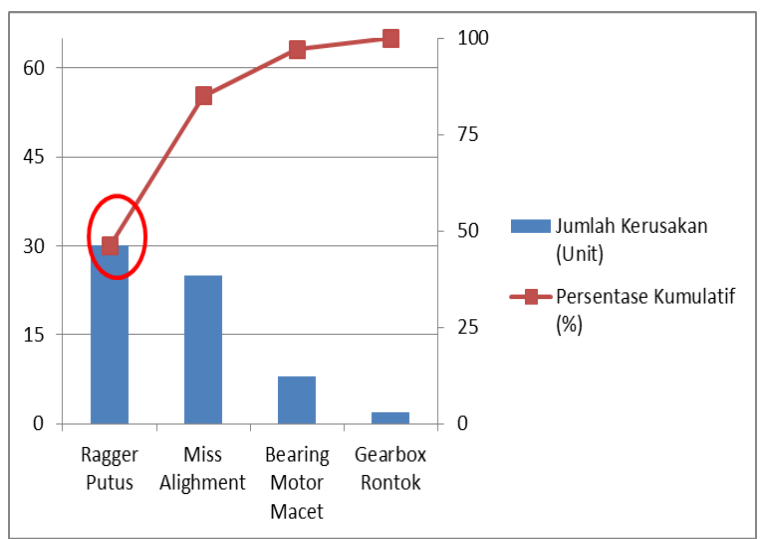

Gambar 1. Diagram Pareto penyebab kerusakan mesin Pulper

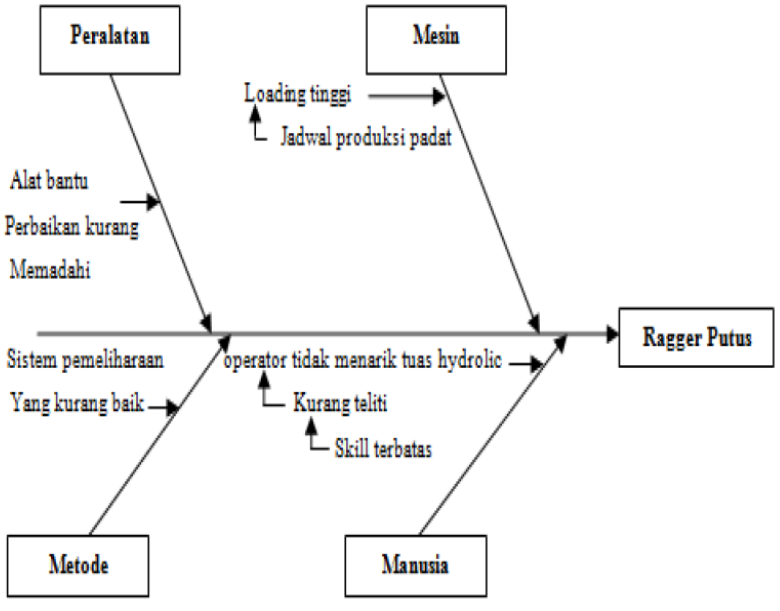

Gambar 2. Diagram Tulang Ikan dari penyebab kerusakan mesin Pulper

Sistem pemeliharaan yang diterapkan di PT Indah Kiat Pulp \& Paper TBK masih belum memadahi, hal ini ditandai dengan kurang idealnya nilai OEE seperti pada tabel 4.3 pada 
bulan April - Desember 2016 nilai OEE < 85\% dan rata - rata per tahun $77.31 \%$. Adapun faktor kurang idealnya nilai OEE yang disebabkan oleh troubleshooting pada kerusakan mesin Pulper dapat dilihat pada diagram Pareto (Gambar 1) dan diagram Tulang Ikan (Gambar 2).
Ragger putus disebabkan beban yang sangat tinggi, sehingga ragger tidak mampu menahan beban yang berlebih yang mengakibatkan putusnya ragger. Usulan perbaikan yang dapat diberikan untuk mengurangi ragger putus secara detail seperti pada tabel 4 .

Tabel 4. usulan perbaikan dari faktor penyebab Ragger Putus

\begin{tabular}{|c|c|c|}
\hline \multirow{4}{*}{$\frac{\text { No }}{1}$} & Faktor - faktor & Penyelesaian masalah \\
\hline & Manusia & \\
\hline & a. Skill terbatas & a. Pelatihan operator mesin secara berkala \\
\hline & b. Kurang teliti & b. Memberi wawasan kepada operator \\
\hline \multirow{2}{*}{2} & 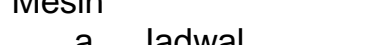 & \\
\hline & $\begin{array}{l}\text { a. Jadwal } \\
\text { produksi padat } \\
\text { b. Loading tinggi }\end{array}$ & $\begin{array}{l}\text { a. Penjadwalan perawatan mesin secara } \\
\text { berkala tidak pada kondisi mesin rusak }\end{array}$ \\
\hline \multirow[t]{2}{*}{3} & Peralatan & \\
\hline & $\begin{array}{l}\text { a. Alat bantu } \\
\text { perbaikan } \\
\text { mesin kurang } \\
\text { memadahi }\end{array}$ & $\begin{array}{l}\text { a. Penyediaan alat bantu untuk } \\
\text { mempermudah operator memperbaiki } \\
\text { mesin yang rusak }\end{array}$ \\
\hline 4 & $\begin{array}{ll}\text { Metode } & \\
\text { a. } & \text { Sistem } \\
& \text { pemeliharaan } \\
& \text { kurang baik }\end{array}$ & $\begin{array}{l}\text { a. Penerapan } \\
\text { maintenance }\end{array}$ \\
\hline
\end{tabular}

\section{KESIMPULAN}

Dari hasil pembahasan tentang Analisis Perawatan Mesin Pulper Menggunakan Metode Overall Equipment Effectiveness dapat diambil kesimpulan bahwa Nilai Overall Equipment Effectiveness mesin pulper selama penelitian diperoleh $77.31 \%$ dengan faktor penyebab mesin Pulper mengalami kerusakan yaitu ragger putus, dengan persentase kerusakan sebesar $46 \%$. Usulan perbaikan yang dapat diberikan untuk meminimalkan kejadian ragger putus adalah pelatihan operator mesin ragger secara berkala, perencanaan perawatan mesin ragger yang terschedule serta penyediaan alat bantu untuk mempermudah operator memperbaiki mesin yang rusak

\section{DAFTAR PUSTAKA}

Bamber, C. J., Castka, P., Sharp, J. M., \& Motara, Y. (2003). Cross-functional team working for overall equipment effectiveness (OEE). Journal of Quality in Maintenance Engineering, 9(3), 223-238.

Chan, F. T. S., Lau, H. C. W., Ip, R. W. L., Chan, H. K., \& Kong, S. (2005). Implementation of total productive maintenance: A case study. International Journal of Production Economics, 95(1), 71-94.

Dal, B., Tugwell, P., \& Greatbanks, R. (2000).
Overall equipment effectiveness as a measure of operational improvement-a practical analysis. International Journal of Operations \& Production Management, 20(12), 1488-1502.

Muchiri, P., \& Pintelon, L. (2008). Performance measurement using overall equipment effectiveness (OEE): literature review and practical application discussion. International Journal of Production Research, 46(13), 3517-3535.

Nakajima, S. (1988). Introduction to TPM: total productive maintenance.(Tr. Productivity Press, Inc.

Suhendra, R., \& Betrianis, B. (2005). Pengukuran Nilai Overall Equipment Effectiveness Sebagai Dasar Usaha Perbaikan Proses Manufaktur pada Lini Produksi (Studi Kasus Pada Stamping Production Division Sebuah Industri Otomotif). Jurnal Teknik Industri, 7(2), 91-100.

Supriyadi, S., Ramayanti, G., \& Afriansyah, R. (2017). Analisis Total Productive Maintenance Dengan Metode Overall Equipment Effectiveness dan Fuzzy Failure Mode and Effects Analysis. SINERGI, 21(3), 165-172.

Swanson, L. (2001). Linking maintenance strategies to performance. International 
Jurnal INTECH Teknik Industri Universitas Serang Raya Vol 3 No 2 Desember 2017, 49-54

p-ISSN 2407-781X

Journal of Production Economics, 70(3), 237-244.

Williamson, R. M. (2006). Using overall equipment effectiveness: the metric and the measures. Strategic Work System, Inc, 1-6. 